\title{
Transient Current of Catalytic Processes at Chemically Modified Electrodes
}

\author{
S. Vinolyn Sylvia ${ }^{1}$, R. Joy Salomi ${ }^{1}$, M.E.G. Lyons ${ }^{2}$, L. Rajendran ${ }^{1, *}$ \\ ${ }^{1}$ Department of Mathematics, Academy of Maritime Education and Training(AMET) \\ Deemed to be University, India \\ ${ }^{2}$ School of Chemistry \& AMBER National Centre, University of Dublin, Trinity College Dublin, \\ Ireland \\ *E-mail: raj_sms@rediffmail.com
}

doi: $10.20964 / 2021.04 .36$

Received: 5 January 2021 / Accepted: 9 February 2021 / Published: 28 February 2021

The model provides reports of diffusion inside the modifier layer situated on the electrode surface of a reactant and charge carrier. This model is based on the system of strongly nonlinear equations containing the nonlinear term related to second-order chemical reaction and Michaelis-type redox reaction. In this paper, approximate analytical solutions are obtained for nonlinear equations under non-steady-state conditions using the well-established homotopy perturbation technique. Lucid and approximate polynomial expressions have been obtained for the reactant, reaction product and charge carrier concentrations and current density. The amperometric current response has been reported as a function of reactant concentration. The numerical simulation of the problem is done using a Matlab programme. The analytical results are compared with simulated data and previously published limiting cases. A reasonable agreement is observed. This paper also presents an analytical expression describing the sensitivity and response time of the biosensor electrode for all values of parameters.

Keywords: Mathematical Modeling, Nonlinear equations, Electrocatalysis, Modified electrodes, Sensitivity of biosensor.

\section{FULL TEXT}

(C) 2021 The Authors. Published by ESG (www.electrochemsci.org). This article is an open access article distributed under the terms and conditions of the Creative Commons Attribution license (http://creativecommons.org/licenses/by/4.0/). 